\title{
PENERAPAN SISTEM RELIGI PADA DESA WISATA BLUE LAGOONDI DUSUN DALEM DESA WIDODOMARTANI KECAMATAN NGEMPLAK KABUPATEN SLEMAN
}

\author{
APPLICATION OF RELIGION SYSTEM IN DESA BLUE LAGOON \\ TOURIST VILLAGEIN WIDODOMARTANI VILLAGE NGEMPLAK \\ SLEMAN REGENCY
}

\author{
Yanuar Kurniadi*,Teguh Kismantoroadji, Eko Murdiyanto \\ Program Studi Agribisnis Fakultas Pertanian \\ Universitas Pembangunan Nasional "Veteran" Yogyakarta \\ Jl. SWK 104, Condong Catur, Depok, Sleman, Yogyakarta, Indonesia 55283 \\ *Email korespondensi :yanuarkurniadi79@gmail.com
}

Diterima tanggal : 9 Juni 2020 ; Disetujui tanggal 15 Juni 2020

\begin{abstract}
This study aims to examine the religious system in the Blue Lagoon Tourism Village and to examine the implementation of the religious system of the Blue Lagoon Tourism Village community. This research used a qualitative approach with the type was a case study approach. The technique of determining the information was purposive sampling, the information being the head of the Tourism Village manager, the head of Dalem sub Village, and the surrounding residents. Testing the validity of the data by means of triangulation namely; interview, observation and documentation. Data analysis techniques in qualitative methods; 1) collecting data, 2) reducing data, 3) presenting data, and 4) drawing conclusions or verification. The results show that the religious system in the Blue Lagoon Tourism Village community namely; symbol system, belief system, value system, and behavior system. The Community of Blue Lagoon Tourism Village has implemented a religious system in social life. But as the development of increasingly modern technology, culture and religion in the Blue Lagoon Tourism Village begin to slowly fade and disappear because people have not been able to use technology properly.
\end{abstract}

Keywords: Religion System and Village Tourism 
Jurnal Dinamika Sosial Ekonomi, 21 (1) : 58-67

\begin{abstract}
ABSTRAK
Penelitian ini bertujuan untuk mengkaji sistem religi yang ada di Desa Wisata Blue Lagoon dan untuk mengkaji penerapan sistem religi masyarakat Desa Wisata Blue Lagoon. Penelitian ini menggunakan pendekatan kualitatif dengan Jenis pendekatan penelitian kualitatif yang digunakan adalah pendekatan studi kasus. Teknik penentuan informan yaitu purposive sampling, informannya adalah kepala pengelola Desa Wisata, kepala dukuh, dan warga sekitar. Pengujian keabsahan data dengan cara triangulasi yaitu; wawancara, observasi, dan dokumentasi. Teknik analisis data dalam metode kualitatif; 1) mengumpulkan data, 2) mereduksi data, 3) menyajikan data, dan 4) penarikan kesimpulan atau verifikasi. Hasil penelitian menunjukkan bahwa sistem religi yang ada di masyarakat Desa Wisata Blue Lagoon yaitu; sistem simbol, sistem keyakinan, sistem nilai, dan sistem perilaku. Masyarakat Desa Wisata Blue Lagoon sudah menerapkan sistem religi dalam kehidupan bermasyarakat. Namun seiring berkembangnya teknologi yang semakin modern, budaya dan religi yang ada di Desa Wisata Blue Lagoon mulai perlahan pudar dan menghilang karena masyarakat belum mampu memanfaatkan teknologi dengan baik.
\end{abstract}

Kata Kunci: Sistem Religi dan Desa Wisata

\title{
PENDAHULUAN
}

Desa Wisata adalah komunitas atau masyarakat yang terdiri dari para penduduk suatu wilayah terbatas yang bisa saling berinteraksi secara langsung dibawah sebuah pengelolaan dan memiliki kepedulian serta kesadaran untuk berperan bersama sesuai ketrampilan dan kemampuan masing-masing memberdayakan potensi secara kondusif bagi tumbuh dan berkembangnya kepariwisataan serta terwujudnya Sapta Pesona sehingga tercapai peningkatan pembangunan daerah melalui kepariwisataan dan memanfaatkannya bagi kesejahteraan masyarakat di wilayah itu.Wisata religi menjadi hal baru yang digemari banyak orang dari berbagai kalangan, mulai dari para penyedia armada wisata, pengelola kawasan ziarah wali, tokoh-tokoh masyarakat, dan masyarakat umum, baik pedesaan maupun perkotaan.

Koentjaraningrat (2009) mendefinisikan religi sebagai sistem yang terdiri dari konsep-konsep yang dipercaya dan menjadi keyakinan secara mutlak suatu umat beragama dan upacara-upacara beserta pemuka-pemuka agama yang melaksanakannya. Sistem religi mengatur hubungan antara manusia dengan 
Kurniadi et.al., Penerapan Sistem Religi Pada Desa Wisata Blue Lagoondi...

Tuhan dan dunia gaib, antara sesama manusia dan antara manusia dengan lingkungannya yang dijiwai oleh suasana yang dirasakan sebagai suasana kekerabatan oleh yang menganutnya.

Desa Wisata Blue Lagoon adalah Desa Wisata yang sangat kental dengan budaya dan religinya. Salah satu budaya yang ada di Desa Blue Lagoon yaitu upacara merti dusun yang diadakan pada saat adanya merti sumber, upacara syawalan, upacara wiwitan dan pentas seni gamelan. Dengan adanya budaya dan religi ini menjadikan masyarakat guyub dan sadar bahwa kebesaran sang maha pencipta yaitu Tuhan Yang Maha Esa. Desa Wisata Blue Lagoon memiliki beberapa tempat wisata religi diantaranya yaitu pemandian (sendang), makam leluhur, dan upacara adat adanya wisata religi karena terdapat tempat - tempat sakral yang di percayai oleh masyarakat Dusun Dalem. Ada 3 pemandian (sendang) yangdiberi nama dengan sendang wadon, sendang lanang, dan sendang pulungan. Sendang - sendang tersebut memiliki keistimewaan khusus bagi orang - orang yang menyakini manfaat yang ada di sendang tersebut. Contohnya dalam meminta hajat kepada yang Maha Kuasa dengan lelaku atau spiritual. Pengelola Desa Wisata Blue Lagoon serta masyarakat Dusun Dalem juga membuat upacara adat yang di beri nama "Merti Sumber" dengan menggabungkan 11 mata air, mata air ini di ambil dari sungai, air laut utara dan selatan serta mengambil dari makam wali - wali kemudian di tuangkan itu menjadi sebuah ritual khusus bagi masyarakat NdalemUntuk upacara adat "Merti Sumber" yang di peringati oleh masyarakat Ndalem dan di hadiri oleh isteri dari pakualam dan sri sultan serta kepala destinasi wisata pada setiap tahunnya. Selain sendang dan upacara adat "Merti Sumber" Desa Wisata Blue Lagoon juga mempunyai destinasi wisata religi makam leluhur yang diberi namaKyai pulungan. Pihak pengelolal sendiri mendapatkan amanah dari leluhurnya untuk membuat sumur di depan makam dengan kepercayaannya bahwa membuat sumur di depan makam akan memberikan kemakmuran untuk dusun dalem tersebut. Dapat dilihat bahwa masyarakat Ndalem sangat kental dengan budaya dan sistem religi. Budaya dan sistem religi yang ada di masyarakat Desa Wisata Blue Lagoon meliputi sistem simbol, sistem keyakinan, sistem nilai dan sistem perilaku. 
Jurnal Dinamika Sosial Ekonomi, 21 (1) : 58-67

Tujuan dalam penelitian ini melihat dari sistem religi yang ada di masyarakat Ndalem, sehingga peneliti merumuskan untuk mengkaji sistem religi yang ada di masyarakat Desa Wisata Blue Lagoondan mengkaji penerapan sistem religi masyarakat yang ada di Desa Wisata Blue Lagoon.

\section{METODE PENELITIAN}

Penelitian dilakukan di Desa Wisata Blue Lagoon,Dusun Dalem, Desa Widodomartani, Kecamatan Ngemplak, Kabupaten Sleman, D.I. Yogyakrta.Karena peneliti tertarik untuk meneliti sisitem religi yang ada di masayarakat Ndalem Desa Wisata Blue Lagoon yang terkenal kental dengan budaya dan sistem religinya. Waktu penelitian dilakukan mulai dari Juli 2019 Agustus 2019.Jenis penelitian yang digunakan adalah penelitian kualitatif. Penelitian kualitatif adalah penelitian yang bermaksud untuk memahami fenomena tentang apa yang dialami oleh subjek penelitian misalnya perilaku, persepsi, motivasi, tindakan, dan lain-lain secara holistik dan dengan cara deskripsi dalam bentuk kata-kata dan bahasa, pada suatu konteks khusus yang alamiah dan dengan memanfaatkan berbagai metode alamiah (Moleong, 2014).

Jenis pendekatan penelitian kualitatif yang digunakan adalah pendekatan studi kasus. Studi kasus merupakan penelitian yang mendalam tentang individu, suatu kelompok maupun organisasi, dan suatu program kegiatan dalam waktu tertentu. Studi kasus menghasilkan data untuk selanjutnya dianalisis untuk menghasilkan teori, studi kasus diperoleh dari wawancara, observasi, dokumen atau arsip, dan dokumentasi.Sesuai dengan jenis penelitian bahwa penelitian kualitatif tidak menggunakan pendekatan populasi dan sampel, tetapi yang digunakan adalah dengan pendekatan secara intensif ke informan. Pada penelitian kualitatif, peneliti memasuki situasi sosial tertentu dengan melakukan observasi dan wawancara kepada orang-orang yang dipandang mengetahui tentang situasi sosial tersebut. Teknik penentuan informan dilakukan dengan cara purposive sampling, yaitu dipilih dengan pertimbangan dan tujuan tertentu serta informan yang ada dalam posisi terbaik dalam memberi informasi yang dibutuhkan 
Kurniadi et.al., Penerapan Sistem Religi Pada Desa Wisata Blue Lagoondi...

(Sugiyono, 2011). Informan dalam penelitan yaitu Ketua pengelola Desa Wisata, Kepala Dukuh, dan Warga Dusun Dalem.

\section{HASIL DAN PEMBAHASAN}

\section{Sistem religi masyarakat yang ada di Desa Wisata Blue Lagoon}

Agama adalah sistem simbol, sistem keyakinan, sistem nilai, dan sistem perilaku yang terlembagakan, yang semua itu berpusat pada persoalan - persoalan yang dihayati sebagai yang paling maknawi (ultimate meaning) (Glock dan Strak,1966 (dalam Ancok dan Suroso, 2005)). Masyarakat Ndalem masih sangat kental dengan budaya dan religinya, tingkat religiuisitas masyarakat akan kepercayaan yang diwariskan oleh para leluhurnya masih sangat tinggi. Masyarakat Ndalem dalam kehidupan sehari - hari menerapkan empat sistem religi yaitu sistem simbol, sistem keyakinan, sistem nilai, dan sistem perilaku. Hal ini sesuai dengan yang dijelaskan Andayani (2009) yang menyatakian bahwa masyarakat menerapkan sistem religi tersebut selain sebagai warisan kepercayaan leluhur juga sebagai rasa syukur kepada Tuhan dan ingin selalu merasa dekat dengan Tuhan. Kepercayaan ini diyakini oleh masyarakat karena sudah menjadi ciri khas dari kepercayaan masyarakat dengan memadukan religi dan budaya yang ada di masyarakat Ndalem. Hal ini sesuai dengan yang dijelaskan Nurul (2019) yang menyatakan bahwa masyarakat menerapkan sistem religi dalam kehidupan sehari - hari karena sudah menerima manfaatnya, masyarakat bisa lebih tenang dalam melakukan aktivitas - aktivitasnya dan terjalin hubungan baik antar masyarakat. Sistem religi merupakan kepercayaan terhadap sesuatu yang dipercayai, namun kepercayaan tersebut tidak lepas dari ajaran Tuhan. Sistem religi juga mengatur hubungan antara manusia dengan Tuhan, ghaib, dan sesama manusia.

Dalam sistem simbol masyarakat Ndalem masih mempercayai dan menghormati peninggalan - peninggalan para leluhurnya seperti, pemandian (sendang), makam leluhur, dan upacara adat. Hal ini sesuai dengan yang dijelaskan Eka (2017) dan Bagus (2018) yang menyatakan bahwa masyarakat sangat mempercayai akan manfaat yang didapatkan setelah mandi di pemandaian 
Jurnal Dinamika Sosial Ekonomi, 21 (1) : 58-67

(sendang) yang ada di Blue Lagoon. Kepercayaan tersebut merupakan salah satu warisan yang ditinggalkan oleh leluhur mereka, masyarakat juga masih menghormati para leluhur mereka dengan mengadakan ziarah kubur dan memanjatkan doa (tahlil) untuk para leluhurnya langsung di makam leluhur, dan masyarakat juga masih menjalankan budaya upacara adat yang ditinggalkan oleh para leluhurnya yang bertujuan untuk menghormatinya dan bersyukur kepada Tuhan atas berkah yang diberikan. Akan tetapi setelah budaya dan religi masyarakat dijadikan wisata, esensi simbol - simbol kepercayaan masyarakat Ndalemmulai pudar.

Pada sistem keyakinan masyarakat Ndalem dalam melalukan aktivitasnya di Desa Wisata Blue Lagoon murni untuk mengenalkan budaya dan religi yang ada di Blue Lagoon kepada masyarakat luar atau wisatawan. Masyarakat secara suka rela menjadi pemandu (tour guide) wisatawan dalam pengenalan budaya yang ada di Blue Lagoon. Masyarakat selalu membantu wisatawan yang berkunjung apabila wisatawan tidak tahu mengenai budaya yang ada di Blue Lagoon dengan sabar dan memberikan penjelasan secara baik dan lengkap. Masyarakat melakukan aktivitas di Desa Wisata Blue Lagoon tanpa paksaan dari siapapun, masyarakat melakukan aktivitas di Blue Lagoon dengan tujuan ingin memajukan Dusun Dalem agar tidak tertinggal dengan dusun - dusun lain.

Pada sistem nilai masyarakat Ndalem menerapkan norma dan aturan yang umum sesuai dengan aturan negara dan syariat agama agar masyarakat atau wisatawan yang berkunjung dapat berlaku selaras dengan norma dan aturan yang ada di Blue Lagoon. Norma - norma yang terdapat pada Desa Wisata Blue Lagoon seperti; norma susila, norma kesopanan, norma agama, dan norma hukum. Norma susila adalah norma yang mendorong manusia untuk berbuat baik serta mencegah manusia untuk melakukan perbuatan buruk karena bertentangan dengan hati nurani manusia yang normal, contoh dari norma susila yaitu mencuri barang milik orang lain, kekerasan sesama manusia, tidak menghormati sesama manusia, dan tidak bersikap jujur. Norma kesopanan adalah ketentuan hidup yang bersumber dari pergaulan masyarakat. Norma ini didasari oleh beberapa hal diantaranya yaitu kebiasaan, kepatutan, kepantasan yang berlaku dalam 
Kurniadi et.al., Penerapan Sistem Religi Pada Desa Wisata Blue Lagoondi...

masyarakat, contoh dari norma kesopanan yaitu menghormati orang yang lebih tua, dan mengikuti norma - norma yang sudah diterapkan oleh masyarakat. Norma agama adalah ketentuan hidup yang bersumber dari Tuhan Yang Maha Esa. Isinya berupa perintah-perintah, ajaran, dan larangan, contoh dari norma agama yaitu tidak melakukan tindakan asusila. Norma hukum adalah ketentuan yang dibuat oleh pejabat yang berwenang yang memiliki sifat memaksa untuk melindungi kepentingan manusia dalam pergaulan hidup di masyarakat dan mengatur tata tertib kehidupan bermasyarakat, contoh dari norma hukum yaitu menaati aturan - aturan yang sudah ditetapkan oleh negara. Norma - norma tersebut adalah bagian dari budaya masyarakat Ndalem, namun masih banyak masyarakat dan wisatawan yang mengabaikan dan melanggar norma - norma yang ada di Blue Lagoon seperti membuang sampah sembarangan, berbicara kasar atau kotor, buang air kecil sembarangan dan meggunakan pakaian oblong dalam mengikuti kegiatan upacara adat. Sehingga kesakralan sistem religi yang ada di Blue Lagoon mulai pudar dan menghilang yang disebabkan oleh masyarakat dan wisatawan yang tidak mematuhi norma dan aturan yang sudah diterapkan di Desa Wisata Blue Lagoon.

Pada sistem perilaku masyarakat Ndalem pada dasar memiliki hubungan yang baik antara pengelola Desa Wisata dan masyarakat sekitar, hal ini sesuai dengan yang dijelaskan Kumara (2013) menyatakan bahwa pengelola Desa Wisata dan masyarakat memiliki tujuan yang sama yaitu ingin memajukan Dusun Dalem agar tidak tertinggal dengan dusun - dusun lain. Kemudian pengelola Desa Wisata membuat obyek wisata malam yang diberi nama Blue Lagoon Night, wisata malam tersebut mulai dilaksanakan pada bulan Agustus 2016 dan antusias wisatawan cukup baik. Melihat antusias wisatawan yang berkunjung pada Blue Lagoon Night, pengelola Desa Wisata Blue Lagoon berinisiatif mengadakan wisata religi. Namun pada pengembangan wisata religi, masyarakat masih kurang mendukung dengan adanya wisata religi di Desa Wisata Blue lagoon. Hal ini dikarenakan masyarakat masih terganggu dengan adanya aktivitas di malam hari dan takut akan adanya perubahan budaya dan religi yang ada di masyarakat Ndalem melalui wisata religi. Masyarakat juga khawatir makam leluhur mereka 
Jurnal Dinamika Sosial Ekonomi, 21 (1) : 58-67

disalahgunakan untuk kegiatan negatif seperti pesugihan, kegiatan tersebut akan berakibat menyekutukan Tuhan dan menyalahi syariat agama. Wisatawan tidak diwajibkan untuk mengikuti norma yang ada di Blue Lagoon dalam melakukan kegiatan spiritual, sehingga wisatawan tidak mendapatkan esensi dari budaya dan religi yang ada di Desa Wisata Blue Lagoon. Akan tetapi pengelola tetap menjalankan wisata religi tersebut. Wisata religi yang ada di Desa Wisata Blue Lagoon dilaksanakan pada hari - hari tertentu yaitu pada hari selasa legi, selasa kliwon, dan jumat kliwon.Hal ini dikarenakan untuk meminimalisir dampak dampak negatif yang dapat memudarkan budaya dan religi yang ada di masyarakat Ndalem.

\section{Penerapan Sistem Religi Masyarakat Desa Wisata Blue Lagoon}

Masyarakat Ndalem pada dasarnya menerapkan sistem religi dalam bermasyarakat. Hubungan baik antar masyarakat terjalin sehingga masyarakat Ndalem terkenal dengan budaya dan religi yang sangat kental, hubungan sosial antar masyarakat seperti gotong royong dan pertemuan bulanan yang dilakukan di Desa Wisata Blue Lagoon dalam menjaga dan melestarikan peninggalan peninggalan leluhur mereka seperti: pemandian (sendang), makam leluhur, dan upacara adat sering dilakukan oleh seluruh masyarakat Desa Wisata Blue Lagoon. Hal ini dikarenakan peninggalan - peninggalan tersebut dipercayai oleh masyarakat membawa berkah untuk Dusun Dalem. Namun kesadaran akan budaya sosial tersebut perlahan - lahan sudah mulai tergerus oleh perkembangan teknologi komunikasi yang semakin modern. Sehingga dalam aspek budaya bermasyarakat tidak lagi diperlukan, karena akibat dari perkembangan teknologi komunikasi tersebut masyarakat menjadi pribadi yang individualis. Pada awalnya kegiatan sosial antar masyarakat seperti rapat Dusun selalu dihadirin oleh masyarakat, setelah adanya teknologi komunikasi rapat Dusun tersebut mulai berkurang masyarakat yang hadir. Hal ini dikarenakan banyak masyarakat yang mensalahgunakan teknologi tersebut dengan meminta hasil rapat tersebut direkam dan dikirim melalui sosial media. Kegiatan gotong royong yang seharusnya dilakukan oleh seluruh masyarakat Ndalem kini hanya sebagian masyarakat saja 
Kurniadi et.al., Penerapan Sistem Religi Pada Desa Wisata Blue Lagoondi...

yang mengikuti kegiatan tersebut. Gotong royong yang ada di masyarakat masih tetap ada namun sudah jarang dilakukan oleh sebagian masyarakat, karena masyarakat cenderung hanya mendokumentasi kegiatan tersebut tanpa mengikuti kegiatan gotong royong. Norma religi yang ada di Desa Wisata Blue Lagoon sudah mulai tidak diperhatikan oleh masyarakat semenjak adanya perkembangan teknologi komunikasi penggunaansmartphone dan internet. Sehingga masyarakat kehilangan kemampuan berbaur dengan masyarakat lain dan cenderung nyaman dengan kehidupan yang modern atau serba mudah.

Masyarakat Ndalem juga akan kehilangan budaya sosial seperti interaksi sosial, karena masyarakat Ndalem sangat terkenal dengan ikatan sosialnya. Hal inisesuai dengan yang dijelaskan Miharja (2015) yang menyatakan bahwa wisatawan membawa budaya ekonomi yang berupa nominal sehingga baik pengelola Desa Wisata maupun masyarakat tidak lagi memperhatikan nilai - nilai sosial yang ada di masyarakat dan membebaskan wisatawan mengikuti kegiatan kegiatan sakral agar dapat menarik wisatawan yang berkunjung demi mendapatkan keuntungan yang berupa uang dari hasil wisatawan yang berkunjung. Budaya - budaya baru yang dibawa oleh wisatawan inilah yang dapat menghilangkan kesakralan pada sistem religi yang dipercayai oleh masyarakat.

\section{KESIMPULAN DAN SARAN}

\section{Kesimpulan}

Sistem religi yang ada di masyarakat Ndalem meliputi sistem simbol, sistem keyakinan, sistem nilai, dan sistem perilaku. Simbol - simbol yang dipercayai masyarakat Ndalem yaitu sendang, makam leluhur, dan upacara adat. Masyarakat Ndalem sudah menerapkan sistem religi dalam kehidupan bermasyarakat. Namun seiring berkembangnya teknologi yang semakin modern, budaya dan religi yang ada di Desa Wisata Blue Lagoon mulai perlahan pudar dan menghilang karena masyarakat belum mampu memanfaatkan teknologi dengan baik. 
Jurnal Dinamika Sosial Ekonomi, 21 (1) : 58-67

\section{Saran}

Pengelola Desa Wisata sebaiknya menerapkan norma budaya dan religi masayarakat Ndalemke dalam wisata religi, sehingga wisatawan mampu mendapatkan esensi dari kegiatan budaya dan religi yang ditawarkan oleh Desa Wisata Blue Lagoon dan tidak menghilangkan kesakralan pada simbol - simbol yang dipercayai oleh masyarakat Ndalem. Pengelola Desa Wisata sebaiknya juga melakukan sosialisi kepada masyarakat terkait pengembangan wisata religi. Masyarakat sebaiknya memanfaatkan teknologi yang canggih seperti smartphone dan internet untuk mepromosikan serta mengenalkan budaya yang ada di Blue Lagoon dengan mendokumentasikan kegiatan - kegiatan budaya yang dilakukan oleh masyarakat, sehingga masyarakat mampu menselaraskan perkembangan teknologi dengan budaya sosial yang ada di Blue Lagoon.

\section{DAFTAR PUSTAKA}

Ancok \& Suroso. (2005). Psikologi Islami: Solusi Islam atas Problemproblem Psikologi. Yogyakarta: Pustaka Pelajar.

Andayani, Ria. (2009). Sistem Religi Pada Masyarakat Kasepuhan Cicarub Provinsi Banten. Jurnal Peneltian dan Budaya. 1 (1) 201 - 213.

Bagus, Ida. (2018). Sistem Kepercayaan Masyarakat di Daerah Aliran Sungai (DAS) Unda Kabupaten Klukung.Jurnal Bahasa dan Budaya. 2 (2) 110 $-117$.

Eka, Kurnia. (2017). Sistem Religi dan Kepercayaan Masyarakat Kampung Adat KutaKecamatan Tambaksari Kabupaten Ciamis. Jurnal Pengabdian Kepada Masyarakat. 1 (4) 236 - 243.

Koentjaraningrat. (2009). Pengantar Ilmu Antropologi. Jakarta: Rineka Cipta.

Kumara, Amitya. (2013). Hubungan Kepercayaan dan Strategi Menyelesaikan Masalah Pada Korban Bencana Gempa Bumi. Jurnal Psikologi. 35 (2) $116-150$.

Miharja, Deni. (2015). Sistem Kepercayaan Awal Masyarakat Sunda. Jurnal Study Lintas Agama. 1 (10) 170 - 181.

Moleong, J.Lexy. (2014). Metode Penelitian Kualitatif. Bandung. PT. RemajaRosdakarya.

Nurul, Sofia. (2019). Sistem Kepercayaan (BELIEF) Masyarakat Pesisir Jepara Pada Tradisi Sedekah Laut. 11 (3) 124 - 140.

Sugiyono. (2011). Metode Penelitian Kuantitatif, Kualitatif, dan R \& D. Bandung: Alfabeta. 